\title{
ALGUNOS DE LOS DESAFÍOS LEGALES Y POLÍTICOS QUE DEBE AFRONTAR EL MOVIMIENTO DE INDEPENDENCIA DE QUEBEC ${ }^{1}$
}

\author{
JEAN-FRANÇOIS GAUDREAULT-DESBIENS ${ }^{2}$ \\ Catedrático de la Canada Research Chair in North America and Comparative Juridical and \\ Cultural Identities \\ Universidad de Montreal
}

\section{SUMARIO}

I. Introducción. II. La consulta sobre la secesión de 1998 como punto de inflexión. III. La Secesión como hecho político y legal. IV. De la Claridad y la Democracia. V. El combate legislativo después de la Consulta sobre la Secesión. VI. El Impacto del Proceso de Referéndum Escocés. VII. El Impacto del Proceso de Referéndum Escocés. VIII. Democracia, Transparencia y el «Derecho a Decidir». IX. Conclusión.

\section{INTRODUCCIÓN}

El movimiento secesionista de Quebec es uno de los más antiguos de ese tipo en un país democrático. Sin embargo, no se ha encontrado en una situación tan desesperada durante décadas. Situación explicable si se tienen en cuenta tanto las estrategias adoptadas como las luchas intestinas recientes, aunque el marco legal para la secesión introducido desde 1998 en Canadá también haya contribuido a ello.

A pesar de esa evolución, la situación de Quebec continúa suscitando interés en otras partes del mundo, en concreto, en Estados democráticos plurinacionales tales como el Reino Unido de Gran Bretaña, España o Bélgica, que han tenido que luchar durante décadas contra la dinámica secesionista. Las compara-

1 Traducción de Santiago Sánchez González, Prof. Emérito de la UNED.

2 Este artículo es una versión ampliada de: J.-F. Gaudreault-DesBiens, «Secession blues: Some Legal and Political Changes Facing the Quebec Independence Movement», (2014) 3 Percorsi Costituzionali 765.

UNED. Teoría y Realidad Constitucional, núm. 37, 2016, pp. 135-162 
ciones entre Quebec, Escocia, Cataluña y el País Vasco, o el Flandes belga, se han convertido casi en una industria artesanal. Sin embargo, las diferencias económicas, sociales, políticas y legales entre esas regiones abundan, aunque compartan el estatus de minoría en el seno de una comunidad política federal o descentralizada.

De todos los desafíos secesionistas, los que atraen mayor atención en Quebec son los de Escocia y Cataluña. Cataluña se parece a Quebec en que su idioma es minoritario en España, como el francés en Canadá, pero a diferencia del francés, el catalán tiene escasa difusión fuera de Cataluña. Los movimientos secesionistas en ambas regiones se basan en suposiciones nacionalistas culturales poderosas, aunque el lugar significativo de Cataluña en la economía española le permite añadir plausiblemente un ingrediente económico a sus reivindicaciones secesionistas. Por otra parte, Quebec y Cataluña poseen regímenes legales notablemente distintos. Los deseos secesionistas de Quebec están anclados en un ordenamiento incardinado en la tradición del common law. En este aspecto se asemeja más a Escocia que a Cataluña.

En cambio, la pretensión de independencia de los secesionistas de Quebec ha sido examinada detenidamente en Escocia y en Cataluña. Realmente, el caso de Quebec se invoca tanto como modelo como anti-modelo y, frecuentemente, las complejidades de la situación de la provincia quedan de paso obscurecidas.

Dicho esto, el objetivo principal de este trabajo no es un estudio comparado; pretende más bien proporcionar a sus lectores una visión general de algunos de los principales obstáculos políticos y legales que afronta en la actualidad el movimiento independentista de Quebec. Podrían extraerse algunas lecciones para los partidos secesionistas en otras partes del mundo; eso es algo que dejaremos al juicio de los lectores. Con todo, el hecho es que la lucha por la independencia de Quebec ha inspirado en buena medida los desarrollos políticos y legales en la forma de plantear las demandas nacionalistas. Aunque sólo fuera por eso, merece la pena volver a examinarlo.

En primer lugar, veremos el marco legal interno aplicable al intento de secesión provincial desde la opinión seminal de 1998, del Tribunal Supremo de Canadá en la Reference re Secession of Quebec ${ }^{3}$, que representó un importante punto de inflexión en el debate sobre la secesión potencial de Quebec (I), en particular por negarse a caracterizar un acto de secesión como puramente legal o político (II), por subrayar la necesidad de claridad en el proceso y el resultado de los referendos sobre la secesión (III) y por provocar reacciones legislativas equiparables en gran parte a política simbólica (IV). Después examinaremos el impacto potencial del proceso del reciente referéndum en Escocia sobre la estrategia del movimiento secesionista de Quebec (V), y los acontecimientos políticos recientes que han revelado profundas divisiones dentro del movimiento nacionalista de Quebec, y

3 Reference re Secession of Quebec, (1998) 2 S.C.R. 217 (en adelante «Quebec Secession Reference). 
que puede haber reducido significativamente su atractivo en partes clave del electorado (VI). Por último, estudiaremos una nueva pretendida base legal para reivindicar la secesión, es decir, el denominado «derecho a decidir», en tanto distinto del derecho a la auto-determinación externa (VII).

\section{LA CONSULTA SOBRE LA SECESIÓN DE 1998 COMO PUNTO DE INFLEXIÓN}

Para entender mejor el marco legal interno aplicable a la potencial secesión de Quebec, debemos apuntar dos observaciones.

Primero, como cuestión de principio, los referendos no tienen efecto legal en derecho constitucional canadiense. Esto se infiere del principio de soberanía parlamentaria, que Canadá heredó del Reino Unido de Gran Bretaña. Según este principio, ninguna asamblea legislativa, sea federal o provincial, puede renunciar a sus competencias legislativas a favor de otro órgano, incluso si ese órgano es «el pueblo» ${ }^{4}$. El resultado de un referéndum es pues meramente consultivo y, en consecuencia, no vincula a ningún legislador; la tradición constitucional británica se inclina por la soberanía del parlamento sobre la del pueblo.

En segundo lugar, antes de la promulgación de la Constitution Act, de 19825, la constitución de Canadá no contenía procedimiento de reforma alguno; las enmiendas se regían por otras normas legales y convencionales ${ }^{6}$. Ahora si incluye dicho procedimiento, pero ninguna cláusula prevé expresamente la hipótesis de una secesión provincial. Algo que hay que mencionar, ya que los cambios constitucionales que llevaron a la inclusión de procedimientos de reforma en la constitución se produjeron después del primer referéndum sobre la secesión de Quebec en 1980. Así, incluso si las modificaciones introducidas por la Constitution Act, de 1982 (por encima de las objeciones de Quebec) fueron provocadas en buena parte por la confusión que rodeó al primer referéndum, no se consideró apropiado incluir una «cláusula de secesión» en la constitución, quizás debido al temor de legitimar ex ante posibles tentativas de secesión. El resultado es que no existía un marco legal claro y transparente cuando se celebró el segundo referéndum sobre la secesión en 1995, lo que condujo a una experiencia cercana a la muerte en Canadá.

La evolución legal post 1995 debe evaluarse con ese telón de fondo. El dato más importante se encuentra ciertamente en la opinión consultiva del Tribunal Supremo de Canadá en la Reference re Secession of Quebec ${ }^{7}$, que, puede esgrimirse

4 In Re Initiative and Referendum Act, (1919) A.C. 935 (J.C.P.C.).

5 Constitution Act, 1982, que constituye el Anexo B de la Canada Act,1982 (U.K.), 1982, c. 11.

6 Re: Resolution to amend the Constitution, (1981) 1 S.C.R. 753.

7 Supra, nota 1. Sobre esta opinión véase entre otros: J.-F. Gaudreault-Desbiens, «The Quebec Secession Reference and the Judicial Interpretation of Conflicting Narratives about Law, Democracy and Identity», (1999) Vermont Law Review, 792. 
que, representa la contribución más significativa del Tribunal a la jurisprudencia contemporánea global. Está fuera del propósito de este comentario realizar un análisis detallado de esa opinión; bastará, por lo tanto con identificar algunos puntos interesantes, todos los cuales conducen a la conclusión de que el Tribunal incorporó a la constitución canadiense una cláusula de secesión judicialmente elaborada, aunque imperfecta.

\section{LA SECESIÓN COMO HECHO POLÍTICO Y LEGAL}

Uno de esos puntos es el rechazo de la antigua reivindicación secesionista de que el silencio alegado de la constitución de Canadá respecto a la secesión de una provincia significaba que no impedía que una provincia se separase y de que, en consecuencia, la secesión era un acto meramente político, situado fuera del ámbito del derecho. En otras palabras, esa demanda se basaba de alguna forma en la idea de que la secesión de una provincia no podría ser caracterizada como una enmienda «ordinaria» de la constitución, dada la magnitud de los cambios implicados. En su lugar, el Tribunal Supremo sostuvo que la secesión de una provincia requería claramente una reforma constitucional formal, sin especificar el tipo de fórmula aplicable ${ }^{8}$. Si Quebec llegara a optar por la secesión, este considerando podría representar una cuestión espinosa, además de producir consecuencias tremendas sobre la concreta factibilidad de la secesión dentro del derecho interno. Incluso asumiendo que los equipos negociadores de los gobiernos implicados en las discusiones que siguieron a los referendos, que involucrarían al menos a los gobiernos federal y de Quebec, se pusieran de acuerdo sobre las modalidades de secesión, el procedimiento de reforma de la constitución necesitaría la ratificación de dicho acuerdo, no sólo del parlamento federal y de la asamblea nacional de Quebec, sino también de las asambleas legislativas de todas las provincias afectadas. Aquí es donde resulta extremadamente importante la identificación del procedimiento de reforma pertinente. De un lado, existe la denominada fórmula «general» de reforma, que precisa de «la aprobación de la Cámara de los Comunes y del Senado del Parlamento federal, y de las asambleas legislativas de los dos tercios de las provincias que representen al $50 \%$ de la población» ${ }^{9}$; por otro, existe el procedimiento de la unanimidad que debe adoptarse para la reforma de las instituciones fundacionales del país ${ }^{10}$. Las opiniones difieren respecto al procedimiento que sería aplicable. Sin embargo, aunque am-

8 Quebec Secession Reference, supra, nota 1, par. 84. Importa señalar que el Tribunal aludió a la posibilidad de juzgar sobre el problema de la fórmula de reforma en caso de producirse una votación positiva sobre la soberanía de Quebec.

9 Este es el resumen de P. Hogg de la sección 38 de la Constitution Act, 1982, supra, nota 2. Véase P.W. HogG, Constitutional Law of Canada (Scarborough: Casrswell, edición de hojas sueltas), n. ${ }^{\circ}$ 5.7(b)

10 Act Respecting Constitutional Amendments, S. C. 1996, c.1. 
bas son exigentes en términos del grado requerido de aprobación por parte de las provincias, la segunda hace muy difícil, si no imposible, introducir modificaciones sustanciales absolutas. Este es el caso cuando los actores políticos no se enfrentan a una crisis tal como la que resultaría como consecuencia de una votación provincial a favor de la secesión. En el supuesto de una crisis grave de la unidad, y a pesar de que el poder ejecutivo controle férreamente al legislativo cuando el gobierno en cuestión es un gobierno de mayoría, existe siempre el riesgo de que las deliberaciones escapen del control y las asambleas se rebelen. Esto es lo que, hasta cierto punto, sucedió cuando el acuerdo de Meech Lake, que reconocía Quebec como «una sociedad diferenciada», fracasó. El acuerdo había sido impulsado por el deseo de inducir a Quebec a firmar la Constitución de 1982, que, aunque legalmente aplicable a la provincia, no había sido, y todavía no ha sido, aceptado, por sus sucesivos gobiernos. Esta atención centrada en Quebec desató un síndrome de «¿por qué no yo?» entre las otras provincias y grupos como los pueblos aborígenes, que pronto manifestaron sus particulares reclamaciones de índole constitucional. En otras palabras, los arreglos asimétricos implican el riesgo de reacciones en cadena que pueden llevar a su fracaso final. Así, mientras que las estrategias de acomodo de las elites que afectan a actores ejecutivos pueden tener éxito, a veces resultan frustradas por asambleas legislativas si los representantes elegidos sienten que el apoyo popular es insuficiente o está desapareciendo. Después del referéndum de Quebec de 1995, se añadió un nuevo obstáculo al procedimiento interno que debe seguirse en el Parlamento federal para la toma en consideración de enmiendas constitucionales multilaterales (como las que se requerirían en el caso de secesión): ningún ministro federal puede presentar una moción autorizando tal enmienda si no la aprobado una mayoría de las provincias, y dicha mayoría debe incluir a Quebec, Ontario, la Columbia Británica y, al menos, dos provincias Atlánticas y dos provincias de la Pradera ${ }^{11}$. Este veto regional legal podría complicar más el proceso de reforma constitucional que teóricamente debería «coronar» una tentativa acertada de secesión desde el punto de vista legal interno.

Si se produjera un bloqueo legislativo después unas negociaciones exitosas post-referéndum entre los gobiernos de Canadá y Quebec, se detendría el proceso legal necesario para dar una forma legal al resultado de las negociaciones, incrementando así el riesgo de una declaración unilateral de independencia por parte de Quebec, en cuyo caso el último arbitro sería con toda probabilidad la comunidad internacional. Ello suscitaría dudas respecto a la importancia, en este punto, del derecho interno de Canadá, puesto que el Tribunal Supremo estableció en la Secession Reference que el voto a favor de la secesión, emanado de la voluntad popular democráticamente expresada no puede ignorarse. A este respecto, el rechazo

11 Act Respecting Constitutional Amendments, S.C. 1996, c.1. N. del T.: Las provincias del Pradera (Prairie Provinces, en el original), son Manitoba, Saskatchewan y Alberta. 
de un enfoque basado exclusivamente en una concepción formalista y legalista de la normatividad constitucional es otro punto de interés de la Secession Reference. Rechazo instrumentado mediante el apoyo del tribunal en principios constitucionales no escritos que son la superestructura intelectual y normativa de la constitución del país, y cuyo papel es «(...) informar y sostener el texto constitucional $(\ldots)^{12}$. Aunque no pueden prevalecer sobre previsiones constitucionales «claras», cabe recurrir a estos principios para colmar lagunas o interpretar textos ambiguos. Y lo que es más importante, en tanto que opuestos a meras convenciones constitucionales, adquieren estatus legal según ha reconocido el Tribunal Supremo, lo que implica que pueden dar lugar, solos o juntos, a obligaciones generales o específicas imponibles a los actores constitucionales. En otros términos, ni los gobiernos ni los tribunales pueden ignorarlos ${ }^{13}$.

El apartamiento del Tribunal Supremo de una lectura estrictamente positivista de la Constitución canadiense le permite elaborar instrumentos con los que comprender mejor cualquier intento potencial de secesión provincial. En el caso en cuestión, los principios no escritos que fueron considerados pertinentes fueron el federalismo, la democracia, el constitucionalismo y el rule of law y, por último, la protección de las minorías. Aunque el Tribunal dedujo varias conclusiones de esos principios, un examen detenido de los mismos está fuera del alcance de este artículo. Nos centraremos en los dos más importantes, que son, a nuestro juicio, las piedras angulares del marco legal actualmente aplicable a la secesión de una provincia de Canadá. Se hallan en el «descubrimiento» de un deber de negociar en determinadas circunstancias y en la exigencia de claridad, algo bastante vago de por sí.

\section{DE LA CLARIDAD Y LA DEMOCRACIA}

La principal novedad constitucional de la Secession Reference reside probablemente en la decisión del Tribunal Supremo, especialmente sobre el fundamento de los principios no escritos de la democracia y del rule of law, de un deber constitucional «de comprometerse a debatir constitucionalmente para reconocer y abordar expresiones democráticas del deseo de cambio en otras provincias» ${ }^{14}$. Este deber es la consecuencia lógica del derecho conferido a los actores federales de iniciar, pero no llevar a cabo unilateralmente, el cambio constitucional. Sin embargo, tomar en consideración este deber debe venir precedido por «una expresión democrática de un deseo de cambio». En este punto, el Tribunal conecta legalidad con legitimidad, ya que la evaluación del carácter democrático de una

12 Quebec Secession Reference, supra, nota 1, par. 49.

13 Id. par. 54

14 Id. par. 69. 
expresión es condición de su legitimidad política, de ahí la exigencia de una «expresión clara de la voluntad de separarse del pueblo de Quebec (... $)^{15}$. El Tribunal equipara «una expresión clara» con una mayoría clara, que debe valorarse cualitativamente, es decir, pensando tanto en la mayoría numérica como en la formulación de la pregunta sobre la que deberá votar la población, que no deberá ser ambigua ${ }^{16}$. Interesa recordar aquí que esta exigencia de claridad se formuló judicialmente en un contexto político en el que se habían celebrado ya dos referendos, antes de que el Tribunal Supremo hiciera pública su opinión en la Secession Reference. Ciertamente no es irrelevante en este punto recoger el texto de las preguntas de los referendos que se plantearon:

Referéndum de 1980: El gobierno de Quebec ha becho pública su propuesta de negociar un nuevo acuerdo con el resto de Canadá basado en la igualdad de las naciones; este acuerdo permitirá a Quebec adquirir el poder exclusivo de aprobar sus leyes, recaudar sus impuestos y establecer relaciones con el extranjero - en otras palabras, la soberanía-y, al mismo tiempo, mantener con Canadá una asociación económica incluyendo una moneda común; cualquier cambio en el estatus politico que resulte de estas negociaciones sólo será ejecutado con la aprobación popular mediante otro referéndum; en estos términos ¿confiere al gobierno de Quebec el mandato de negociar el acuerdo propuesto entre Quebec y Canadá?

Referéndum de 1995: ¿Está de acuerdo en que Quebec sea soberano después de haber realizado un of recimiento formal a Canadá de asociación económica y política en el ámbito del proyecto de ley relativo al futuro de Quebec y del acuerdo firmado el 12 de junio de 1995?

El Tribunal puede verdaderamente haber tenido in mente esas preguntas cuando estableció el umbral de la pregunta clara/ mayoría clara en la Secession Reference, y mantuvo que la presencia de una mayoría clara sobre una pregunta clara activaría la aplicación de la obligación constitucional de «negociar los cambios constitucionales para responder a ese deseo» ${ }^{17}$. Esta «respuesta» implicaría «reconocer y respetar esa expresión de voluntad democrática iniciando las negociaciones y desarrollándolas conforme a los principios constitucionales no escritos ya discutidos ${ }^{18}$. El Tribunal establece claramente que este deber de negociar no puede interpretarse en el sentido de que el gobierno federal y las otras provincias estén en la obligación de «acceder a la secesión de Quebec, sujeta solamente a la negociación de los detalles logísticos de la secesión ${ }^{19}$. Además, a pesar de su naturaleza constitucional, el deber de negociar no sería justiciable, dejando su aplicación a los actores políticos. Si ellos no llegaran a acordar los términos de la secesión y, en consecuencia, sobre si se han comportado o no en una manera que satisfaga la obligación de negociar, se produciría una situación de anomia, por no

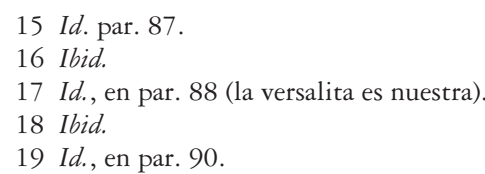


decir más, y agotaría con toda probabilidad los recursos del derecho interno, una posibilidad que el Tribunal expresamente admitió ${ }^{20}$. Así, una secesión provincial en orden en el contexto canadiense implicaría respeto por la democracia y el rule of law; empero, es muy posible que en algún momento, y a falta de un acuerdo sobre los términos de la sucesión, el rule of law interno podría ceder ante el rule of law internacional ${ }^{21}$.

Dada su dimensión ex ante, frente a la aplicación ex post facto del denominado «deber de negociar», no sorprende que sea el requisito de la claridad el que ha causado la impresión más duradera desde la emisión de la opinión del Tribunal Supremo en la Secession Reference. La falta de claridad de las preguntas del referéndum de 1980 y de 1995 ha sido central en los debates que entonces se dieron, al menos en el lado federalista. En verdad, en un contexto en el que la opinión preferida de los ciudadanos de Quebec ha sido siempre, y lo sigue siendo, una versión renovada del federalismo, más descentralizado y flirteante con una genuina confederación (por improbable que pueda ahora parecer esta hipótesis), cualquier pregunta que aluda al mantenimiento de alguna forma de vinculaciones con $\mathrm{Ca}$ nadá difícilmente puede plantearse sin ambigüedad. Esto es, la pregunta de 1995 sobre la conversión de Quebec en soberana — nótese la ausencia de las palabras independencia o secesión- «¿después de haber ofrecido formalmente a Canadá una nueva asociación política y económica dentro del ámbito del proyecto de ley relativo al futuro de Quebec y del acuerdo firmado el 12 de junio de 1995?» El proyecto de ley en relación con el futuro de Quebec, nunca promulgado como ley dada la derrota de la opción secesionista, preveía que después de un voto afirmativo, la Asamblea Nacional de la provincia estaría «apoderada para proclamar la soberanía de Quebec», aunque estaría obligada a proponer la asociación mencionada en la pregunta del referéndum. La asociación incluiría «instituciones políticas conjuntas» y, más concretamente, un Consejo, un Secretariado, una Asamblea y un Tribunal para la resolución de los conflictos. Además el tratado que estableciera la asociación "garantizaría que la asociación tiene (tendría) autoridad para actuar» sobre la unión aduanera, la libre circulación de mercancías, individuos, servicios y capital, política monetaria, movilidad laboral y ciudadanía. La soberanía de Quebec habría sido declarada después de concluir el acuerdo sobre el tratado de asociación. Sin embargo, y lo que es más importante, el proyecto de ley establecía un periodo de un año después del referéndum para lograr una acuerdo sobre el tratado. De no suscribirse el acuerdo, la Asamblea Nacional quedaría apoderada para realizar una declaración unilateral de soberanía.

La pregunta de 1995 ¡era clara? Sí, en la medida en que una lectura cuidadosa del proyecto de ley podría verdaderamente llevarle a uno a entender que el

20 Id., en par. 103

21 Para un análisis reciente de la dimensión legal internacional de la secesión, véase: J. DugGARD, The Secession of States and Their Recognition in the Wake of Kosovo (The Hague: AIL.-Pocket, 2013). 
resultado último del proceso sería una declaración de independencia, con asociación o no. No, en la medida en que inducía a la población creer, sobre todo su preámbulo, que una asociación sería casi inevitable, dado el inveterado embrollo de las economías de Quebec y de Canadá. Un problema adicional era que la pregunta meramente refería a los documentos que aclaraban que el resultado último de un voto afirmativo significaría la secesión de la provincia —obviamente no había garantía alguna de que los votantes hubieran leído esos documentos. En cierto modo, la soberanía absoluta, es decir, la soberanía sin asociación alguna, era presentada casi como una opción derivada y de último recurso. Los votantes difícilmente podían ignorar lo que había en las papeletas, especialmente después de una campaña sobre el referéndum en la que el lado federalista interpretó esa pregunta en el sentido de que conduciría a la independencia, pero también podía llevarles a creer que la asociación era un ingrediente igualmente importante.

Curiosamente, por no decir irónicamente, un libro reciente de entrevistas con los actores políticos principales del referéndum de 1995 revela que los dos líderes principales de la campaña del «si», el antiguo Premier Jacques Parizeau y el entonces líder del Bloque quebequés Lucien Bouchard, tenían opiniones muy distintas de lo que sucedería después de una votación afirmativa. Para Parizeau la independencia era su principal objetivo, con o sin asociación. Bouchard, por su parte, prefería una nueva asociación semejante a la de la Unión Europea; además, creía que sería necesario un segundo referéndum para confirmar el nuevo estatus constitucional de Quebec ${ }^{22}$. Esto podía ser fácilmente interpretado como prueba de la falta de claridad de la pregunta planteada en 1995.

\section{EL COMBATE LEGISLATIVO DESPUÉS DE LA CONSULTA SOBRE LA SECESIÓN}

La insistencia de la Secession Reference en la claridad, asumida por el Parlamento federal cuando aprobó en el año 2000 la Clarity $A c t^{23}$, en la que proporciona su propia interpretación de las exigencias de claridad de la Consulta, animado como lo estaba a hacerlo por la decisión del Tribunal Supremo de que el proceso de referéndum no sería judicialmente controlado.

En pocas palabras, esta Ley impone a la Cámara de los Comunes la obligación de considerar, durante cierto plazo, cualquier pregunta presentada en una asamblea legislativa provincial «relativa a la secesión de esa provincia de Canadá», y determinar si es o no está clara ${ }^{24}$. Con ese fin, debe examinar «si la pregunta daría como resultado una expresión clara de la voluntad de la población de una

22 C. Hébert \& J. Lapierre, Confessions post-référendaires. Les acteurs politiques de 1995 et le scenario d'un oui (Montréal: Éditions de l'Homme, 2014), pp. 33-34.

23 Clarity Act, S.C. 2000, c.26.

24 Id. par. 1 (1). 
provincia sobre si la provincia debería dejar de ser parte de Canadá y convertirse en un estado independiente ${ }^{25}$. En una referencia clara a las preguntas de referéndums anteriores, la Ley proponía que:

(...) una expresión clara de la voluntad de la población de una provincia en el sentido de que la provincia deje de formar parte de Canadá no podría resultar de (a) una pregunta en el referéndum que meramente se centre en un mandato de negociación sin pedir una expresión directa de la voluntad de la población de esa provincia sobre si la provincia debería dejar de formar parte de Canadá; o (b) una pregunta en el referéndum que prevea otras posibilidades además de la secesión de la provincia de Canadá, tales como acuerdos económicos o políticos con Canadá, que obscurezcan una expresión directa de la voluntad de la población de esa provincia sobre si la provincia debería dejar de ser una parte de Canadá ${ }^{26}$.

Así pues, la Clarity Act establece un régimen para determinar si, después de un referéndum, hay una mayoría clara a favor de la secesión de la provincia, como condición previa para que el gobierno federal entable negociaciones con la provincia secesionista. La ley, por lo tanto, prevé una evaluación en dos fases, primera sobre la claridad de la pregunta del referéndum después de que ha sido presentada; luego, de la claridad de la mayoría favorable al referéndum después de que este se celebre. Conviene apuntar aquí que mucho tiempo antes de la promulgación de esta Ley, el gobierno federal había participado en dos referendos en Quebec, aunque no se pronunció sobre la elaboración de la pregunta y aunque todo el proceso se desarrolló sometido al derecho quebequés. Incluso en 1992, cuando se celebró un referéndum pan-canadiense sobre el Acuerdo de Charlottetown -un proyecto destacado de reforma constitucional-, el referéndum en el territorio de Quebec se rigió por el derecho provincial, mientras que en el resto de las provincias y territorios lo hizo por el derecho federal. No sorprende, por lo tanto, que la promulgación de la Clarity Act fuera recibida con indignación en los círculos nacionalistas de Quebec, porque era la primera vez que el gobierno federal afirmaba un derecho a influir en el procedimiento mismo del referéndum más que en los puros resultados del referéndum. Desde luego, esta influencia es indirecta en el sentido de que la Clarity Act no se aplica a la Asamblea Nacional de Quebec; el gobierno de esta provincia puede formular la pregunta que quiera, pero corre el riesgo de ser rechazada ab initio por la Cámara de los Comunes, si no es lo suficientemente clara. Sin embargo, expone la posición del gobierno federal ante un componente crítico del proceso de referéndum antes del mismo referéndum, es decir, la pregunta, y en realidad evita que el gobierno entable negociaciones con una provincia secesionista si la Cámara de los Comunes no ha establecido que ambos, la pregunta del referéndum y el voto mayoritario en favor de la secesión, 
están claros. Con todo, según este tratamiento, el gobierno federal podría ser tomado como rehén por la Cámara de los Comunes lo que, en tiempo de crisis, podría bloquear cualquier determinación de la claridad de la pregunta o la mayoría, actuando así de mala fe y colocando al gobierno federal ante el riesgo de incumplir su obligación constitucional de negociar, incluso en una situación que posiblemente generaría dicha obligación.

Como reacción ante la Clarity Act federal, la Asamblea Nacional de Quebec adoptó enseguida, bajo la dirección del gobierno secesionista del Premier Lucien Bouchard ${ }^{27}$, un Act Respecting the Fundamental Rights and Prerogatives of the Québec People and the Québec State (Ley relativa a los derechos fundamentales y prerrogativas del pueblo y del Estado de Quebec) ${ }^{28}$, que pretendía inter alia reafirmar el derecho del pueblo de Quebec a la auto-determinación ${ }^{29}$ y el de sus instituciones políticas a «determinar solas la forma de ejercer su derecho a elegir el régimen político y el estatus legal de Quebec ${ }^{30}$. Asimismo, postulaba que en el caso de referéndum, «la opción ganadora será la opción que obtenga una mayoría de los votos válidos emitidos, a saber, el $50 \%$ de los votos válidos emitidos más uno» ${ }^{31}$. Interesa destacar que aun cuando cierta elite nacionalista y la mayoría de los medios de comunicación fueron muy críticos de la Clarity Act, y partidarios del Act Respecting the Fundamental rights and Prerogatives of the Québec People and the Québec State, la población de la provincia no se movilizó en contra de la iniciativa federal, que finalmente llevó a la dimisión del Premier Bouchard.

Desde ese combate legislativo de los tempranos años 2000, el marco legal interno de la secesión no ha cambiado: la Secession Reference sigue siendo la pieza central, mientras que la Clarity Act y el Act Respecting the Fundamental Rights and Prerogatives of the Québec People and the Québec State aún enmarcan lo que los gobiernos federal y quebequés podrían hacer si Quebec quisiera separarse de Canadá. Pero ninguno puede pretender razonablemente haber resuelto todos los dilemas suscitados por la claridad de la pregunta del referéndum y de la mayoría que debiera lograrse. Decir que algo está «claro» implica una interpretación previa y significa un acto de autoridad que trata de poner fin a un debate ${ }^{32}$; sin embargo, debería subrayarse que la Secession Reference no confiere a ningún actor político involucrado, voluntariamente o no, en un referéndum provincial sobre secesión con autoridad absoluta sobre el procedimiento o el resultado. Realmente, la cla-

27 Bouchard se convirtió en el líder del Partido quebequés después de la dimisión del Premier Jacques Parizeau, a renglón seguido de la derrota de la opción secesionista. Puesto que el PQ continuaba en el poder, Bouchard sucedió a Parizeau como Premier de la provincia.

28 S.Q., 2000 , c. 46 , s. 2.

29 Id., s. 1-2.

30 Id., s. 3.

31 Id., s. 4.

32 M. VAN DE KerChOVE, «Le sens clair d'un texte: argument de raison ou d'autorité?», en G. HAARSHer, L. IngBer \& R. VANDER Elst (eds.), Arguments d'autorité et arguments de raison en droit, (Brussels: Éditions Némésis, 1988), p. 291. 
ridad puede evaluarse mejor contextualizándola; como es obvio, la pregunta y el resultado de la votación son problemas de importancia fundamental, pero en esta evaluación pueden influir otras variables. Por ejemplo, ¿qué dijeron los protagonistas políticos durante el debate? Desde esa perspectiva, estas normas ejemplifican lo que podría denominarse como legislación política.

\section{EL IMPACTO DEL PROCESO DE REFERÉNDUM ESCOCÉS}

La situación ideal es sin duda aquella a la que llegaron Westminster y Edimburgo en el caso de Escocia, es decir, un acuerdo en torno a la pregunta y la mayoría, así como el compromiso de ambos sobre el procedimiento si la respuesta resultara positiva. Mediante cooperación previa, crearon un precedente político significativo para otros referéndums sobre la secesión. Sin embargo, este precedente no es fácilmente extrapolable al contexto canadiense. En realidad, como apuntamos antes, Quebec sola estableció las reglas del juego en los dos referendos pasados sobre la secesión, lo que impidió, una vez iniciado el proceso, la participación en el debate del gobierno federal. Y desde entonces Quebec ha negado al gobierno federal toda legitimidad para intervenir en el proceso. Por otra parte, Canadá, después de la Clarity Act, tiende a asumir una posición de superioridad moral y a retratar al secesionismo quebequés como un movimiento regresivo monolítico, para negarle cualquier forma de legitimidad, lo que inevitablemente imposibilita reconocer, en un acuerdo pre-referéndum, que esa opción es legítima y podría incluso ganar, y que Canadá de alguna forma tendría que valorar, además de mostrar interés en facilitar en lo posible la transición. Finalmente, para que se hiciera realidad la hipótesis de un acuerdo bilateral pre-referéndum, habría que modificar en algunos aspectos tanto la Clarity Act, como el Act Respecting the Fundamental Rights and Prerogatives of the Québec People and the Québec State, lo que con toda probabilidad provocaría intensos debates. En última instancia, puede ser que mientras que la población en Quebec y en Canadá podría dar su apoyo a una solución estilo escocés, la carga de la tradición antagonista actual podría evitar que se ejecutara en la esfera política.

Pero las expectativas de la población sobre la claridad no desparecerán de un día para otro, lo cual puede representar un problema para el movimiento secesionista de Quebec. Como se comprobó, las dos primeras preguntas de referéndum no eran inequívocas, pues ambas se referían, directa o indirectamente, a la posibilidad de una asociación renovada entre Quebec y Canadá. La razón por la que se formularon así por los gobiernos declaradamente secesionistas es simple: sabían muy bien que los quebequeses abrumadoramente preferían un federalismo renovado o un acuerdo como el de la Unión Europea antes que una separación total de Canadá. Pero la estrategia de moderar la opción secesionista con vistas a atraer a la mayoría del pueblo para que votara «si» en los referendos puede haber resultado anti-productiva a la larga, ya que la independencia de Quebec nunca se pre- 
sentó como la mejor opción, aun teniendo en cuenta los inconvenientes asociados con aquélla. El proponente principal de la secesión, o sea, el Partido Quebequés, nunca se atrevió a alegar directamente que el florecimiento cultural y lingüístico de Quebec —la justificación primordial del movimiento secesionista— compensaba los diferentes costes asociados con la independencia, por elevados que fuesen. En lugar de ello, trató de calmar los temores sobre esos costes ocultando, o incluso negando, su existencia. Esto fue, y sigue siendo, un obstáculo doméstico significativo para el movimiento. Empero, pude haber más obstáculos en el futuro, en particular en el plano internacional. Además de que no se ha producido ni una tentativa de secesión que haya culminado con éxito en las décadas pasadas en un Estado occidental democrático económicamente avanzado — la desintegración de Checoslovaquia fue lo más parecido a una implosión-, el proceso de Escocia pudo haber elevado el listón en términos de las expectativas de la comunidad internacional en torno a la secesión. $Y$ esto pudo ser causa de preocupación para los secesionistas de Quebec, porque puede haberles forzado a atenerse al principio de la claridad, viendo así, a corto plazo, reducidas sus probabilidades de ganar alguna vez un referéndum. Al mismo tiempo, siempre es difícil anticipar como habría reaccionado la comunidad internacional en el caso de que los escoceses hubieran votado claramente en favor de la independencia. A este respecto, ni los federalistas ni los secesionistas pueden confiar en el resultado del proceso escocés para reforzar cualquier argumento planteando la cuestión del reconocimiento internacional de un Quebec independiente en un futuro debate.

Teniendo en cuenta lo expuesto, mientras que el marco legal potencialmente aplicable a una secesión unilateral de Quebec genera numerosos inconvenientes, existe una variable que sin duda explica mejor el estado de ánimo deprimido de los secesionistas de Quebec en la actualidad, esto es, el agravamiento de las desavenencias dentro de las filas nacionalistas entorno a lo que Quebec es, o debería ser.

\section{LOS INFORTUNIOS DEL NACIONALISMO QUEBEQUÉS}

El nacionalismo de Quebec es viejo; surgió en un contexto en el que la mayoría franco-hablante se vio marginada en Canadá y en la esfera económica provincial. Esta situación precaria, combinada con las características lingüísticas y religiosas del grupo, condujo al desarrollo de un nacionalismo que giraba en torno a la defensa de los intereses culturales, políticos y económicos de la mayoría. Era, en resumen, un nacionalismo étnico. A partir de los años 1960, la sociedad de Quebec experimentó una rápida modernización, se secularizó y el gobierno provincial fue investido con la responsabilidad de promover la identidad diferenciada del pueblo quebequés. Se abandonó la antigua referencia de los quebequeses franco-hablantes a su identidad franco-canadiense y se remplazó por la afirmación de una identidad de Quebec, partiendo de la idea de que los quebe- 
queses franco-hablantes deberían ser los dueños de su propia casa y de un nacionalismo de afirmación debía prevalecer sobre el nacionalismo de supervivencia que profesaron una vez. Legal y políticamente, llevó a la realización de políticas públicas informadas por el nacionalismo metodológico ${ }^{33}$, que, a su vez, alimentó una lógica de individualismo posesivo ${ }^{34}$. Esta lógica ha conducido a considerar las competencias constitucionales como objetos de propiedad que deben ser inexorablemente adquiridos. En este proceso, se confiere sistemáticamente a los conflictos jurisdiccionales, incluso a los de menor importancia, un valor identitario significativo que sirve para elevarlos al estatus de fetiches nacionales. Esta dinámica, sin duda, y quizás paradójicamente, contribuyó a quebrantar la atracción del secesionismo de Quebec en el pueblo. Esto puede atribuirse a lo que metafóricamente nosotros calificaríamos de «el síndrome ique viene el lobo!» Ciertamente es razonable suponer que la «identitarización» (sic) de todos los objetos potenciales de la jurisdicción constitucional —que hemos denominado en otro lugar una manifestación de fetichismo constitucional ${ }^{35}$ - , desencadena una dinámica de trivialización de la mayoría, si no de todos los objetos de la jurisdicción, como resultado del cual todos pierden su prominencia, aun cuando la población podría seguramente movilizarse contra ellos. En otros términos, la constante reiteración de argumentos basados en una mitología de victimización sistemática puede derivar en una fatiga constitucional.

Dicho lo cual, la re-definición de la identidad descrita anteriormente no se produjo, sin embargo, sin aporías. En verdad, el cambio de una identidad étnica franco-canadiense no territorializada diseminada por toda la federación, pero con concentración mayor en Quebec, a una identidad política territorializada centrada en Quebec, definida principalmente por la lengua, planteó el interrogante de qué hacer con todos aquellos residentes en Quebec que no eran de descendencia francesa o que ni siquiera eran hablantes de francés. ¿No reunían los requisitos necesarios para ser considerados como quebequeses? La respuesta abrumadora dentro de los principales círculos nacionalistas/secesionistas desde los 1960 a los 1990 fue «sí». Empero, se pidió a esos ciudadanos que aceptaran la primacía del francés como lengua del común y, en última instancia, como la única lengua oficial de Quebec, con sujeción a los derechos constitucionales de la minoría anglo-parlante. En una federación con dos lenguas oficiales (francés e inglés), en la que una de ellas (la inglesa) es claramente dominante, dicha demanda no era pequeña proeza.

33 Vid. A Wimmer \& N. Glick Schiller, «Methodological Nationalism and Beyond: Nation-State Building, Migrations, and Social Sciences», (2002) 4 (2) Global Networks 301.

34 Vid. C.B. Macpherson, The Political Theory of Possessive Individualism: Hobbes to Locke (Oxford): Oxford University Press, 2010 (1962).

35 J.-F. Gaudreault-Desbiens, «The Fetichism of Formal Law and the Fate of Constitutional Patriotism in Communities of Comfort: A Canadian Perspective,» en: J.E. Fossum, P. MagnetTe \& J. Poirier (eds.), Ties That Bind. Accommodating Diversity in Canada and the European Union (Brussels: Bern \& Berlin, P.I.E. Peter Lang, 2009), p. 301. 
Esta mirada superficial a la reinvención del nacionalismo de Quebec revela una profunda tensión en su seno: ¿cómo puede pretender ser «cívico» y por lo tanto teóricamente inclusivo de todos los ciudadanos si, al mismo tiempo, fomenta prácticamente una agenda política y cultural que refleja la experiencia de la mayoría, tratando esencialmente de esa forma de promover los intereses de la última? Más allá de ilustrar el relativo carácter artificial de la dicotomía étnico/ civil, este interrogante plantea un asunto importante respecto a la secesión: puesto que el nacionalismo y el secesionismo están generalmente entrelazados - y en ningún sitio es más cierto que en Quebec-, ¿cómo puede un proyecto secesionista, informado por lo que puede percibirse como una concepción cosmética de nacionalismo cívico, atraer a todos los ciudadanos? En este sentido, la concepción cívica de la nación de Quebec, adoptada por el principal partido secesionista, el Partido Quebequés, de la provincia, se había centrado fundamentalmente en la lengua francesa como la lengua de uso común de la provincia. Después de la conmoción inicial causada por la adopción de la Charter of the French Language en $1977^{36}$, un modus vivendi frágil, pero real, surgió, y si los anglófonos y los alófonos resistieron en buena medida la llamada de las sirenas secesionistas, se sintieron sin embargo cada vez más inmersos en la corriente principal de Quebec. Entre tanto, la demografía de la provincia fue cambiando con la inmigración. Más concretamente, la inmigración de países hablantes del francés fue considerada como un medio de asegurar el florecimiento de esa lengua en Quebec. Pero, esos emigrantes no solamente traían la lengua francesa en el equipaje, sino otras cosas, como la religión.

En el año 2007 se inició un feroz debate en torno al «razonable acomodo» de la religión en los tribunales ${ }^{37}$. En breve, esta doctrina, adoptada por el Tribunal Supremo de Canadá, establece que cuando una norma en apariencia neutra infringe indirectamente el derecho a la igualdad de uno o su libertad religiosa, la victima puede solicitar una adaptación individualizada que debe concedérsele, a menos que la organización desde la que demanda demuestre que su concesión causaría penalidades indebidas. Si bien la doctrina se ha venido aplicando durante muchos años sin problemas a diversos tipos de demandantes, incluyendo a mujeres embarazadas y personas con minusvalías físicas, un conjunto de casos que implicaban adaptaciones religiosas captaron la atención de los medios de comunicación y de políticos, y comenzó la denominada «crisis de la adaptación razonable», que, en último término llevó al gobierno a crear una comisión de inves-

36 The Charter of the French Language, R.S.Q. c. C-11, hizo del francés la única lengua oficial de la provincia, limitó el uso de lenguas distintas del francés en la publicidad y obligó a todos a enviar a los niños a escuelas francesas, son sujeción a los derechos conferidos a los canadienses anglo-parlantes.

37 Para un análisis socio-legal de este debate, véase: J.-F. Gaudreault-Desbiens, «Religious Challenges to the Secularized Identity of an Insecure Polity. A Tentative Sociology of Quebe's Reasonable Accomodation Debate,» en R. Grillo, P. Shah, A. Hoekema, et. al. (eds.), Legal Practice and Cultural Diversity (London: Ashgate, 2009, p. 151) 
tigación co-presidida por el sociólogo Gérard Bouchard y el filósofo Charles Taylor, que presentaron un destacado informe, que confirmó que no existía un problema manifiesto con la adaptación religiosa y calificaba cuanto había sucedido de «crisis de percepción» ${ }^{38}$. Al mismo tiempo, advirtieron la resistencia de la inseguridad cultural de la mayoría franco-hablante y las posibles reacciones excesivas a que podría llevar. El proceso que condujo al informe de Bouchard-Taylor pacificó en algún modo el debate, pero el mismo informe fue archivado en su mayor parte por el gobierno liberal a la sazón en el poder.

Lo que resulta interesante es que mientras el debate de 2007 fue alimentado por los media y por algunos políticos, los intelectuales neo-conservadores ${ }^{39}$ - todos nacionalistas y la mayoría de ellos secesionistas - se habían apropiado de la inseguridad subyacente de la mayoría franco hablante, que básicamente sostenían que el giro cívico del nacionalismo de Quebec era el resultado de la cesión de la elite intelectual y política a los ideales del multiculturalismo, asociado a una estratagema federal ideada a ahogar a la comunidad nacional formada por Quebec en el crisol multicultural canadiense. Esta postura intelectual, que Maclure etiqueta de «romántico-conservadora», mantiene que «la 'mayoría histórica» (quebequeses de origen franco-canadiense) por alguna razón perdió su capacidad de adquirir poder e independencia y autoafirmación políticas cuando se abrió a la pluralidad $»^{40}$.

El episodio del 2007 había revelado claramente la resistencia de una suerte de susceptibilidad identitaria en el seno de la mayoría franco-canadiense de Quebec. El Partido Quebequés secesionista trató de aprovecharla después de haber ganado poder en 2012. En el 2013 presentó un proyecto de «Carta de valores» que se convirtió formalmente en una «Carta del laicismo» cuando se presentó en la Asamblea Nacional un proyecto de ley para hacerla efectiva ${ }^{41}$. En lo esencial, pretendía imponer una forma de laicismo muy enérgico, inspirado mayormente en la idea francesa de laicité. Su punto central era una prohibición global de los signos religiosos ostensibles que llevaran los empleados del sector público y de organizaciones subvencionadas por el gobierno. Oficialmente se prohibieron todos los signos religiosos ostensibles, incluyendo las «cruces grandes». El proble-

38 Commission de Consultation sur les Pratiques D'accommodement Reliées aux Différences Culturelles, Fonder l'avenir. Le temps de la conciliation (G. BOUCHARD \& C. TAYLOR, co-chairs), (Quebec: Commission de Consultation sur les Pratiques D’Accommodement Reliées aux Différences Culturelles, 2008).

39 Para una formulación reciente de sus tesis, véanse, entre otros: M. Bock-Côté, Fin de cycle. Aux origines du malaise politique québécois (Montréal: Boréal, 2012); J. BEAUCHEMIN \& L. BEAudoin, «Le pliuralisme comme incantation», Le Devoir, February 13, 2010, p. C5.

40 J. Maclure, «Quebec's Culture War: Two concepts of Quebec Identity», en S. GervaIs, C. KIRKEY \& J. Rudy (eds.), Quebec Questions. Quebec Studies for the Twenty-First Century (Oxford: Oxford University Press, 2011), pp. 137, 138.

41 Charter affirming the values of State secularism and religious neutrality and of equality between women and men, and providing a framework for accommodation requests, Bill 60, 40 ${ }^{\text {th }}$ Legislature, first Session, National Assembly, Quebec Official Publisher, 2013. 
ma es que en una sociedad muy secularizada, en la que la influencia de la Iglesia Católica, antes un protagonista político importante, es ahora en el mejor de los casos marginal, poca gente lleva «cruces grandes». Pero un buen número de mujeres musulmanas lleva velo. Así, en la práctica, esta carta del laicismo habría tenido un efecto desproporcionado sobre las minorías religiosas.

Curiosamente, los argumentos esgrimidos por el gobierno para presentar este proyecto de ley evolucionaron en el curso del debate; comenzó con una justificación genérica, en apariencia neutra, normativa; lentamente, derivó en juicios de valor sobre creencias y conductas, y culminó en discursos descaradamente islamofóbicos, que no emanaban directamente del propio gobierno, pero que eran tolerados cuando procedían de algunos de sus más prominentes seguidores.

En primer lugar, la defensa del proyecto se basaba en el laicismo y en la consiguiente necesidad de crear un espacio perfectamente «neutro», en el que la libertad de conciencia del pueblo no se viera turbada por signos religiosos cuya utilización se asociaba con el proselitismo. Se alegó, además, la necesidad de protección de la igualdad de las mujeres, supuestamente amenazada por los dictados religiosos; en este contexto, se retrataba a las mujeres que llevaban signos religiosos como víctimas de una falsa conciencia. Por último, en su justificación se invocaba que era un medio de defender los «valores de Quebec» —-incluyendo el laicismo y la igualdad de género (sic) — frente a la amenaza externa del islamismo.

Si bien algunos miembros del gobierno pueden haber creído sinceramente en la necesidad de abordar de forma enérgica el laicismo, el ímpetu inicial para la adopción de este proyecto era, sin duda, movilizar a la base electoral del gobierno secesionista e instrumentalizar la inseguridad cultural de la mayoría franco-canadiense, con el fin de lograr la mayoría parlamentaria que no pudo conseguir un año antes. La estrategia consistía en crear una suerte de polarización de «nosotros» frente a «ellos», o, si se prefiere, una dicotomía amigo/enemigo de la que hablaba Carl Schmitt ${ }^{42}$. Dado que las encuestas mostraban un fuerte apoyo para su proyecto de Carta entre el electorado franco-hablante, el gobierno del Partido Quebequés convocó elecciones para marzo de 2014, en las que el federalista Partido Liberal estableció el itinerario. Lo que sucedió fue que el Partido Liberal hizo campaña en la posición ambigua del Partido Quebequés sobre la secesión, lo cual asustó al electorado, incluso a sectores del mismo que apoyaban la política del gobierno. Desde esa perspectiva, las elecciones del 2014 muestran claramente que fuera de los círculos secesionistas de línea dura, se tiende a considerar la secesión como un sueño no realista o, aún peor, repulsivo. Pero la relación de las consecuencias del laicismo parecen todavía más catastróficas para el movimiento secesionista de Que-

42 Vid. S. Mancini, «The Tempting of Europe, the Political Seduction of the Cross. A Schmittian Reading of Christianity and Islam in European constitutionalism,» en S. MANCINI \& M. RosenfELD (eds.), Constitutional secularism in an Age of Religious revival (Oxford: Oxford University Press, 2014), p. 111.

UNED. Teoría y Realidad Constitucional, núm. 37, 2016, pp. 135-162 
bec, porque ha revelado divisiones profundas y quizás irreconciliables dentro del movimiento respecto al tipo de sociedad en que se convertiría un Quebec independiente. En este sentido, la escisión entre los nacionalistas «romántico-conservadores» y pluralistas que el proyecto de Carta ampliaba, ha acelerado la implosión del Partido Quebequés como principal portador de la idea de la independencia, y ha fortalecido a otros partidos más pequeños que han comenzado a reivindicar los valores izquierdistas y pluralistas, que fueron durante mucho tiempo parte integrante del propio programa político del Partido Quebequés. Más allá de esta disputa interna, lo peor para el movimiento secesionista de este episodio es la ruptura de la comunicación con los grupos minoritarios en la provincia. Históricamente, a pesar del moderado éxito electoral entre estos grupos, el Partido Quebequés había hecho serios esfuerzos para legitimar su opción vis-à-vis estos grupos. La mayoría de esos esfuerzos son ahora ruinas humeantes, ya que algunos de ellos fueron las víctimas directas del proyecto de Carta. Los musulmanes se encontraban entre sus objetivos principales, aunque muchos de ellos habían abrazado la causa de la independencia de Quebec por sus afinidades con la mayoría franco-hablante — los nacionales franco-hablantes de los países del Magreb representan una proporción significativa de los inmigrantes de Quebec.

En resumen, la re-emergencia del nacionalismo étnico y su aceptación por el Partido Quebequés, como lo demuestra la Carta del laicismo ahora difunta que presentó cuando formaba gobierno, puede haber asestado un golpe casi mortal a la causa que preconiza. Lo más asombroso de todo esto es que en buena medida es un golpe auto-infligido.

\section{DEMOCRACIA, TRANSPARENCIA Y EL «DERECHO A DECIDIR ${ }^{43}$}

Enfrentado a lo que cada vez parece como un callejón sin salida política y legal, un sector del movimiento secesionista de Quebec parece inclinado a tomar en consideración vías más radicales y previamente descartadas hacia la independencia. Tal es el caso de Option Nationale, un partido político muy pequeño pero sorprendentemente influyente que opina que unas meras elecciones serían suficientes para desencadenar un proceso de secesión. Esta postura sigue siendo marginal, ya que los principales partidos secesionistas son plenamente conscientes de la necesidad de un referéndum para aumentar la probabilidad del reconocimiento internacional de una declaración unilateral de independencia. En otras palabras, de alguna manera aceptan, aunque de mala gana, la opinión del Tribunal Supre-

43 En este apartado desarrollamos un argumento utilizado inicialmente en: J.-F. GAUdREAULT-DesBIENS, «¿Un derecho 'legal' a decidir?», La Vanguardia, agosto 8, 2015, p. 17. 
mo de Canadá según la cual ni el derecho interno de Canadá, ni el derecho internacional confiere a Quebec un derecho legal a separarse unilateralmente que estaría basado en el derecho a la auto-determinación exterior.

En ese contexto, y a raíz de debates similares en Escocia y en Cataluña, se ha invocado cada vez más un pretendido «derecho a decidir», de significado distinto del ya reconocido derecho a la auto-determinación, pero no de forma enérgica o tan frecuentemente como en Cataluña. Existe una buena razón que explica esa discrepancia: Canadá nunca ha negado a Quebec la posibilidad de celebrar un referéndum sobre la independencia. A este respecto, la negativa del gobierno español a tomar en consideración la idea de que los catalanes puedan expresar sus opiniones sobre el estatus constitucional de su comunidad, es difícil de aceptar desde la perspectiva canadiense, prescindiendo de lo correcto o incorrecto de las posturas secesionistas y unionistas. Sin embargo, en contra de la tesis defendida por algunos secesionistas en Quebec y en Cataluña, dicha expresión difícilmente podría dimanar de un «derecho» legal «a decidir», e implicar consecuencias normativas formales sobre esa base.

Cierto es que la expresión de opiniones de una comunidad política sobre su estatus constitucional, en el marco de un debate democrático al que todos los interesados, incluyendo el estado central, están llamados a participar, es muy importante desde el punto de vista democrático. Esto lo reconoció el gobierno canadiense participando en los dos referéndums en los que la posible secesión de Quebec estaba en el orden del día. También lo admitió el Tribunal Supremo de Canadá en su opinión consultiva de 1998, en la que el Tribunal subrayó, basándose en el principio constitucional de la democracia, que una expresión de un deseo de cambio del estatus constitucional de una provincia, podría dar origen a un deber de negociar de todas las partes concernidas, incluso si dicho cambio pudiera en última instancia llevar a la secesión. Sin embargo, tratándose solamente de una obligación relativa a los medios, ese deber de negociar no garantizaría un resultado concreto. En otras palabras, no es seguro que una negociación produjera los resultados satisfactorios para las expectativas populares, como podría haberlo sido en el tiempo de la votación. Además, cualquier modificación del estatus constitucional de la provincia derivada de tal negociación tendría que realizarse mediante una reforma constitucional formal. A decir verdad, el principio democrático que proporciona el fundamento para la obligación de negociar, no puede ocultar otro principio importante, a saber, el rule of law. Y si las negociaciones fracasaran y de ello siguiera una declaración unilateral de independencia, dicha declaración sería ilegal según el derecho interno. Si en algún momento hubiera existido una justificación para la «salida» de la provincia, habría que hallarla en el derecho internacional. Pero el derecho a una auto-determinación externa reconocida por el derecho internacional no es aplicable a la situación de una provincia como Quebec, que no puede en rigor ser considerada como sometida a alguna suerte de dominio extranjero. Aquí es donde la pretendida existencia de un derecho legal a decidir aparece en la ecuación. 
Pero tratar de fundamentar legalmente una declaración unilateral de independencia en tal pretendido derecho podría resultar extremadamente peligroso. Aun así, la Asamblea Nacional de Quebec aludió de algún modo a ese «derecho» en el Act Respecting the Fundamental Rights and Prerogatives of the Québec People and the Québec State ${ }^{44}$. En realidad, en respuesta al Clarity Act del parlamento federal, la Asamblea Nacional manifestó formalmente que «el derecho del pueblo de Quebec a la auto-determinación se funda en el hecho y en el derecho» ${ }^{45}$, que «tiene el derecho inalienable de decidir libremente el régimen político y el estatus legal de Quebec» ${ }^{46}$, y que, «actuando mediante sus propias instituciones políticas», «determinará solo el modo de ejercer su derecho a escoger el régimen político y estatus legal de Quebec» ${ }^{47}$. Se podría interpretar este tipo de legislación declarativa como una mera manifestación de bravuconada legislativa, pero eso sería tomar a la ligera un discurso que pretende realizar un cambio semántico en el mismo concepto de «derecho», es decir, transformar, lo que en el mejor de los casos sería un derecho moral, en un derecho $\operatorname{legal}^{48}$. Dicho cambio semántico probablemente incrementará la confusión en relación con lo que realmente dice el derecho positivo sobre el derecho de autodeterminación de los pueblos, que continúa siendo el criterio jurídico reconocido en derecho internacional, y suministrará un falso sentido de seguridad a los votantes, porque les induce a suponer un derecho ex ante, cuya existencia tiene todavía que demostrarse ${ }^{49}$. El hecho es que el derecho internacional positivo no puede interpretarse en el sentido de reconocer un «derecho» absoluto a la secesión que estaría basado en un «derecho» genérico a decidir. Es precisamente ese tipo de «derecho", que tiene poco que ver con un derecho reconocible por un ordenamiento legal legítimo, el que la legislación de Quebec del 2000 pretendió proteger al tiempo que lo convertía en absoluto. Curiosamente, la afirmación de un «derecho a decidir», si se entiende que ese derecho implica consecuencias legales positivas, empuja al movimiento secesionista un paso adelante. Como han apuntado dos autores canadienses hace poco, la dificultad que encuentran pequeñas naciones integradas en estados democráticos mayores al recurrir al derecho de auto-determinación externo, para fundamentar legalmente el intento de secesión, había llevado durante algún tiempo a muchos nacionalistas o secesionistas a cambiar su discurso de una justificación legal de

\footnotetext{
44 Supra, nota 26.

45 Id., s. 1.

46 Id., s. 2

47 Id., s. 3.

48 Pende todavía un cuestionamiento constitucional sobre el fondo de esa norma: Tribunal Superior de Quebec, District of Montreal, n. ${ }^{\circ}$ 500-05-065031-013.

49 La ambigüedad semántica del derecho a decidir tal como se utiliza en Cataluña ha sido documentada y analizada en: S. Sierra \& J.J. Olivas, «On the Right to Decide», London School of Economics, Euro Crisis in the Press: The Politics of Public Discourse in Europe, December 6, 2013, on line: http://blos.lse.ac-uk/ eurocrisispress/2013/12/06/on-the-right-to-decide/.
} 
esa tentativa ex ante, a una ex post facto, basada en el principio de la efectividad $^{50}$. Sin embargo, la invocación de un «derecho a decidir» distinto del derecho a la autodeterminación externa significa en cierto modo una desviación del argumento de la efectividad y una vuelta a una forma de justificación ex ante ${ }^{51}$.

De acuerdo con sus más recientes promotores $^{52}$, y hay varios en Cataluña ${ }^{53}$, este «derecho» a decidir tendría su origen legal principal en la opinión consultiva del Tribunal Internacional de Justicia de 2010, en el caso de la declaración unilateral de independencia de Kosovo. En realidad, se hace referencia a ciertas afirmaciones del Tribunal, como las siguientes: 1) el alcance del principio de integridad territorial se limita a las relaciones entre Estados ${ }^{54}$; 2) ninguna norma de derecho internacional prohibiría las declaraciones unilaterales de independencia ${ }^{55}$ a menos que esa declaraciones vayan acompañadas de violaciones importantes de normas de ius $\operatorname{cogens}^{56}$; 3) las opiniones difieren en lo relativo a «si, fuera del contexto de territorios y pueblos no auto-gobernados sometidos a la subyugación, al dominio y a la explotación, el derecho internacional de auto-determinación confiere a parte de la población de un Estado existente un derecho a separarse de dicho Estado» ${ }^{57}$; o 4) los autores de la declaración unilateral de independencia de Kosovo no estuvieran obligados por el marco constitucional al que estaban sujetos según el derecho doméstico ${ }^{58}$. Los promotores de un «derecho a decidir» legal vieron en esas frases un fundamento que confirma la naturaleza jurídica de ese pretendido «derecho».

Incluso dejando de lado la discutible ligereza de algunas de las afirmaciones del TIJ en su opinión sobre Kosovo, interpretándola como si sirviera de fundamento a un «derecho», es decir, a una pretensión válida, a decidir, resultaría dudoso, con el debido respeto, por tres razones al menos. En primer término, esa interpretación generaliza el alcance de las afirmaciones realizadas en relación con un caso dimanante de un contexto fáctico muy concreto, o sea, de un Estado

50 F. Bérard \& S. Beaulac, Droit à l'indépendence. Québec, Monténégro, Kosovo, Écosse, Catalogne (Montréal: XYZ éditeur, 2015), p. 250, nota 13.

51 Importa señalar que el Tribunal Constitucional español, en su opinión sobre la Declaración de soberanía y del derecho a decidir del pueblo de Cataluña. interpretó este pretendido «derecho a decidir» como si existiera en el seno de las estructuras del Estado español, es decir, como susceptible de realización mediante el ejercicio del derecho a la auto-determinación interna. STC 42/2014, de 25 de marzo de 2014.

52 Véase, por ejemplo, el trabajo de mi colega D. TuRP, Le droit de décider du peuple catalán, December 10, 2013, on line: http://danielturpqc.org/upload/2013findoc/Turp_Le_droit_de_decider_du_Parlement_ catalan_10_decembre_2013_Version_finale.pdf.

53 Véase, por ejemplo: J. López, «A Right to Decide? On the Normative Basis of a Political Principle and its Application in the Catalan Case», en: K.J. Nagel \& S. Rixen (eds.), Catalonia in Spain and Europe. Is There a Way to Independence? (Baden-Baden: Nomos, 2015), p. 28.

54 Accordance with International Law of the Unilateral Declaration of Independence in respect of Kosovo, Advisory Opinion, I.C.J. Reports 2010, p.403, \$80.

$55 \mathrm{Id} ., \S 79$.

56 Id., $\$ 82$.

57 Ibid.

$58 I d ., \S 120$.

UNED. Teoría y Realidad Constitucional, núm. 37, 2016, pp. 135-162 
nacido después de una guerra sangrienta ${ }^{59}$. Al mismo tiempo, descontextualiza las citadas afirmaciones y deja al margen la mayoría de los matices de que precisa. En segundo lugar, obscurece el hecho de que el TIJ se niega a resolver «los debates relativos a la extensión del derecho a la auto-determinación y la existencia de cualquier derecho de «secesión terapéutica», sin embargo, (que) se refiera al derecho a separarse de un Estado» ${ }^{60}$. Tercero, y lo que es más importante, esa interpretación ignora de propósito la diferencia entre un derecho positivo ex ante a hacer algo y la inferencia, según se trate, de consecuencias legales de una situación de hecho, cuya existencia es independiente del ejercicio de un derecho positivo previo a crearla. Recuérdese que el TIJ distingue la cuestión suscitada en el caso de Kosovo del que fue sometido a la consideración del Tribunal Supremo de Canadá en la Secession Reference de 1998. El TIJ, en realidad, apunta en su opinión que el Tribunal Supremo «se preguntó si existía un derecho a «llevar a cabo una secesión», y si existía una norma de derecho internacional que otorgara una titularidad positiva a cualquiera de los órganos nombrados», en tanto que la Asamblea General ha solicitado al TIJ que se pronuncie sobre «si la declaración de independencia se había realizado «de acuerdo con» el derecho internacional», lo que equivalía a preguntar si el derecho internacional aplicable prohibía o no la declaración de independencia ${ }^{61}$. Por lo tanto, el Tribunal menciona que no se le ha pedido que resuelva si Kosovo tenía un derecho positivo a declarar su independencia unilateralmente, ni «a fortiori, (...) si el derecho internacional confiere un derecho a los entes dentro de un Estado a romper unilateralmente con él» ${ }^{62}$. Además añade que «es perfectamente posible que un acto concreto - como una declaración de independencia unilateral - no viole el derecho internacional, pero no por ello constituya necesariamente el ejercicio de un derecho otorgado por él» ${ }^{63}$.

La interpretación más amplia (y más generosa) posible, que puede hacerse de esos comentarios del TIJ, es que el derecho puede, en ocasiones, ex post facto, extraer algunas consecuencias legales de una situación de hecho que tiene que tomar en consideración, pero cuya existencia no depende del ejercicio de un derecho positivo previo pretendidamente reconocido en el derecho internacional. El que no se viole el ordenamiento legal internacional no implica la creación per se de derechos, ni, a mayor abundamiento, el derecho a infringir un ordenamiento legal interno. En otras palabras, nada en la opinión sobre Kosovo abona el reconocimiento de un derecho a decidir en un sentido estrictamente jurídico, que fuera independiente del derecho a la auto-determinación. Es más, como observa

59 Para la naturaleza sui generis de Kosovo, vid. V. Piergigli, «Il Kosovo e la secession assistita», (2014) 3 Percorsi costituzionali 699

60 Supra, note $52, \S 83$.

61 Id., $\$ 56$.

62 Ibid.

63 Ibid. 
John Duggard (antiguo juez ad hoc del Tribunal Internacional), la práctica no proporciona base alguna para argumentar que la aplicabilidad del derecho a la auto-determinación no es una condición necesaria para crear un nuevo Estado ${ }^{64}$.

Si en el derecho internacional no existe un derecho legal general y absoluto a decidir, afirmar continuamente su existencia constituye, sin embargo, una estrategia discursiva políticamente eficaz. Aunque sea engañosa. Realmente, sería más exacto decir que resulta eficaz porque es engañosa. A decir verdad, hablar de un «derecho» a decidir produce cierto efecto de representación teatral, en el sentido de que es susceptible de inocular en la mente de aquellos que en última instancia «decidirán», la creencia de que el acto de secesión está de antemano en consonancia con el derecho internacional. La confusión, hábilmente albergada, entre un derecho legalmente reconocido y un derecho cuya aspiración máxima es que se le considere como «moral» refleja un movimiento político de cosmética que trata de calmar los temores de los ciudadanos, que podrían de otra manera tener dudas sobre la tranquilidad de las secuelas de una «decisión» favorable a la secesión. Esto es cierto para los quebequeses, pero muy posiblemente también para los catalanes, vascos, escoceses o flamencos.

Conviene recordar aquí que uno de los aspectos más significativos de la opinión del Tribunal Supremo de Canadá, en la Consulta sobre la Secesión, gira en torno a los requisitos que establece, relativos a la calidad del proceso que se considera conducirá a la expresión democrática de una voluntad que activaría un deber de negociar. Al exigir que la pregunta planteada en el referéndum y la mayoría obtenida favorable al cambio propuesto fueran claras, el Tribunal hizo hincapié en la necesidad de transparencia en el proceso que finalizaría con la secesión de una provincia. Recuerda así al público el hecho de que expresar una opinión es un gesto cualitativamente diferente de adoptar una decisión. Una decisión implica una elección cuyas consecuencias deben ser razonablemente averiguables, y cuyos términos deber ser formulados de la manera más clara posible. $\mathrm{La}$ intensidad de este requisito de la claridad, aplicable a todas las fases del proceso, aumenta dependiendo de la importancia y de la irreversibilidad de la opción que se adopte. Desde esa perspectiva, no está claro que unas meras elecciones, aun cuando sea descrita por algunos partidos políticos como un cuasi-referéndum, cumplirían con ese requisito. Realmente, incluso cuando una pregunta concreta se convierte en el asunto principal de unas elecciones, las divisiones políticas pre-existentes, o temas ocasionales pueden condicionar el resultado; e incluso cuando la cuestión de la secesión es el centro del debate, no se plantea necesariamente en términos que son absolutamente claros. Y si un partido pro-secesionista logra convertir esa pregunta en el asunto principal de la campaña electoral, algunos votantes podrían apoyar esa opción justo para presionar al gobierno central para que responda a sus demandas, sin desear verdaderamente una separación

64 J. DugGard, op.cit. nota 19, p. 270. 
total. La secesión se convierte así en un triunfo que se utiliza para modificar una relación de poder. En este contexto, difícilmente podrá caracterizarse de clara la «respuesta» dada a las elecciones. Lo que suceda después del proceso puede también causar problemas. Por ejemplo, un gobierno secesionista recien elegido podría tratar de instrumentalizar para sus propios propósitos el debate con el gobierno central que su elección activaría y, en particular, tratar de socavar cualquier negociación susceptible de llevar a un estatus político menor que el de un estado independiente, lo que sería considerado como una disolución del mismo proyecto secesionista. En tales circunstancias, es probable que no sea tan difícil exacerbar el sentimiento de victima en la población e inducirla a apoyar, mediante un referéndum o de otra manera, un proyecto de declaración unilateral de independencia. Así, el proceso desencadenado por unas elecciones convertido en un referéndum conducirá inevitablemente, si ganan los partidos secesionistas, a una acción secesionista oficial. En otras palabras, la dinámica política en juego conlleva el riesgo de hacerlo irreversible. Eso es posiblemente lo que Jacques Parizeau, que era el premier secesionista de Québec cuando el referéndum de 1995, pensaba cuando dijo que después de un voto afirmativo a favor de la opción secesionista, los quebequeses quedaría atrapados como langostas en una jaula. Con esa hipótesis in mente y volviendo al «derecho» a decidir que justificaría en principio esa estrategia, no es ilegítimo después de todo formularse la siguiente pregunta: ¿el derecho a decidir qué?

El problema es que ese tipo de estrategia se defiende con frecuencia en nombre de la democracia. Está bien, las referencias a la voluntad democráticamente expresada del pueblo son a menudo poco más que sortilegios tipo mantra, pero hay que reconocer el lirismo nacional compensa a veces la falta de transparencia del proceso en cuyo contexto se manifiesta esa voluntad. Por eso precisamente, es deseable la imposición de criterios jurídicos determinados en cuyo marco se desenvuelvan los procesos políticos, sobre todo con vistas a asegurar que el proceso sea transparente y menos susceptible de instrumentalización. Por desgracia, invocar un vago «derecho» a decidir que carece de fundamento legal alguno, plantea más problemas que aporta soluciones.

La cuestión aquí no es decir que los estados, que son comunidades políticas históricamente contingentes, no pueden disolverse, no obstante argumentos en contra, fundados o no en disposiciones constitucionales explícitas. Más bien, se trata de concretar que, salvo pocas excepciones, no existe tal cosa como un derecho positivo a disolverlos. Esto es cierto incluso para los estados federales constituidos luego de un proceso de agregación. A decir verdad, una vez que esas entidades han creado una federación, la federación se convierte en un ordenamiento legal distinto de aquellas, al que se inviste de ciertos poderes soberanos que se protegen constitucionalmente ${ }^{65}$.

65 C. Sснмiтt, Théorie de la constitution, (Paris: Presses Universitaires de France, 1993), p. 513. 
Pues bien, una cosa es decir que no existe un derecho positivo a disolver un estado mediante una acción secesionista, en concreto, una declaración unilateral de independencia, y otra, decir que la secesión es totalmente imposible. Como apunta el TIJ en su opinión sobre Kosovo, dicha declaración no constituiría en sí una violación del orden legal internacional, incluso si representa una violación del ordenamiento interno del estado afectado por esa declaración. De acuerdo con ello, el derecho internacional podría en última instancia, ex post facto, extraer consecuencias legales de la nueva situación fáctica en la que se encontraría Québec. Sin embargo, el reconocimiento internacional del nuevo estado no puede darse por descontado. Como indicó Milena Sterio ${ }^{66}$, uno no puede ignorar el hecho de que el éxito de cualquier proyecto secesionista está en gran medida determinado por la reacción de los estados que pueden ser calificados de «poderes principales». En este sentido, resulta mas bien difícil identificar cual sería el interés de dichos poderes en consentir la disolución de una democracia avanzada como la de Canadá. La misma observación puede hacerse respecto a países como el Reino Unido de Gran Bretaña, Bélgica o España.

El examen del caso de Francia vis-à-vis Québec puede resultar interesante a ese respecto. Teniendo en cuenta las afinidades lingüísticas y culturales con Québec, así como la soberanía de Canadá, Francia ha seguido desde siempre con Québec una política de «no intervención, no indiferencia», que ha dado origen a expectativas entre los círculos secesionistas de que si Quebec se separase, Francia reconocería inmediatamente al nuevo estado, y presionaría a otros estados a hacer lo mismo. En breve, esa era la aventura que el gobierno de Québec estaba dispuesto a emprender en $1995^{67}$.

Ciertamente, podría haber sucedido y todavía puede suceder. Pero esta hipótesis parte de la base de que Francia habría estado o estaría en la actualidad dispuesta de asumir el riesgo de inquietar a socios próximos europeos que se están enfrentando a sus propios movimientos secesionistas. Y además deja de lado el problema interno planteado por Córcega. De manera que incurre en una petición de principio: más allá de todo el bello discurso diplomático que exalta las virtudes de la proximidad cultural entre Francia y Québec, ¿estaría Francia dispuesta a desconocer las preocupaciones de sus socios europeos y a apoyar sin reservas una declaración de independencia de Québec? Dado el peso de la realpolitik en los asuntos internacionales y la defensa histórica de Francia de la noción de la raison d'État, cabe legítimamente plantearse dudas al respecto. Lo que Francia, y otros poderes podrían hacer, sin embargo, sería presionar al gobierno canadiense para que no aplazase indebidamente las negociaciones después de que se hubiera producido un voto secesionista en un referéndum, para evitar el estímulo de la ines-

66 M. STERIO, «On the Right to External Self-Determination: "Selfistans”, Secession and the Great Powers Rule», (2010) 19 Minnesota journal of International Law 137.

67 C. Hébert \& J. LApierre, op. cit., nota 20, p. 53.

UNED. Teoría y Realidad Constitucional, núm. 37, 2016, pp. 135-162 
tabilidad. En realidad, aunque los grandes poderes prefieren la estabilidad y tienden a oponerse a proyectos secesionistas que surgen en las democracias desarrolladas, podría alcanzarse un punto en el que las preocupaciones por la estabilidad les llevaran a apoyar proyectos secesionistas democráticamente fundados, si el hecho de no respetar una votación clara favorable a la secesión, condujera posiblemente a la inestabilidad. Pero todo esto, téngase presente, se produce ex post facto y no depende, o confía, en un derecho ex ante.

En última instancia, volvemos a empezar de cero, por así decirlo: naciones pequeñas, pero no dominadas o perseguidas de otra forma, como Quebec o Cataluña difícilmente pueden reivindicar un «derecho» legal genérico a decidir, que sería distinto del derecho a la auto-determinación externo reconocido en el derecho internacional en circunstancias excepcionales. Es perfectamente posible que se autorice un régimen legal internacional regulador de las condiciones de ejercicio del derecho a la auto-determinación por naciones sub-estatales, añadido en los estados democráticos. Tal régimen, podría suponerse, extraería consecuencias legales del principio de democracia y tomaría en consideración las cuestiones relativas a la legitimidad política, a fin de reducir el impacto negativo de las respuestas oficiales y ultra-dogmáticas a los desafíos secesionistas, como las manifestadas por Madrid en el caso de Cataluña, o por Francia respecto a Córcega ${ }^{68}$.

Pero todavía no existe, y afirmar lo contrario, basándose en una interpretación amplia en exceso de la opinión del TIJ en el caso de Kosovo es, en el mejor de los casos, errónea, pues si no concurren las circunstancias que justificarían el ejercicio del apropiado derecho a la autodeterminación externa, el reconocimiento de operaciones secesionistas sigue siendo una cuestión eficacia, como las dificultades adicionales que comporta.

\section{CONCLUSIÓN}

Hemos pretendido en este texto llamar la atención sobre los obstáculos legales y políticos con los que se enfrenta actualmente el movimiento secesionista en Quebec. Aunque será difícil superarlos, sería prematuro anunciar la muerte del paciente, pues mientras exista una «pequeña nación» diferenciada del resto de Norteamérica por su «profunda diversidad» ${ }^{69}$, el nacionalismo desempeñará un papel en la política de esta nación. Y la secesión será siempre una opción razonable a los ojos de muchos. Ciertamente, muchos quebequeses sienten sinceramen-

68 Véase la decisión del consejo constitucional de este país en: Décision sur le Statut de la Corse, Conseil Constitutionnel français, decisión n. ${ }^{\circ}$ 91-290, 9 mayo 1991, JO mai 1991, p. 6350.

69 C. TAYLOR, "Convergences et divergences à propos des valeurs entre le Québec et le Canada», en Rapprocher les solitudes. Écrits sur le fédéralisme et le nationalisme au Canada (Québec: Presses de l'Université Laval, 1992), pp. 179, 212-213. 
te como si se encontraran en una suerte de «exilio interior» dentro de Canadá ${ }^{70}$, dado el rechazo de Quebec del orden constitucional actual. Los cambios políticos de los últimos diez años en el ámbito federal tampoco sirven de ayuda: las políticas del ala derecha del gobierno conservador, que perdieron recientemente el poder, suelen estar reñidas con los valores de los quebequeses, como se ha visto en varias elecciones, dada la casi ausencia de representación conservadora de Quebec. El distanciamiento de Quebec de Canadá podría haberse incrementado ante el nacionalismo mayoritario ${ }^{71}$ que informaba las políticas federales, si bien discreta e informalmente: pertenecer a una Anglo-esfera puede atraer a algunos canadienses, pero no es un argumento convincente en Quebec. Tampoco parece una estrategia muy fiable contar con la desafección de la juventud al secesionismo. Las elecciones provinciales del 2014 mostraron que los votantes jóvenes de hoy no tienden a priorizar la independencia de Quebec sobre otros temas, incluso si su sentimiento de pertenencia a Canadá parece bastante débil. El hecho de que estén más interesados por los derechos humanos, los problemas medioambientales, y el equilibrio entre la vida laboral y familiar, y que sean más cosmopolitas que sus antepasados, tampoco significa que su conexión con Canadá aumente cualitativamente. En el mejor de los casos, muchos de ellos son agnósticos cuando se trata de su identidad canadiense. En consecuencia, contar con las nuevas generaciones para desactivar la amenaza de la secesión podría ser pretencioso. Por ello resulta un tanto prematuro escribir el obituario del movimiento secesionista quebequés.

Empero, los recientes debates en torno al laicismo y al sentimiento de exclusión, si no de rechazo total, que muchos grupos minoritarios han experimentado, arroja luz sobre un problema más hondo que afronta no sólo Quebec, sino posiblemente todos los movimientos nacionalistas/secesionistas cuyo programa político gira principalmente alrededor de reivindicaciones lingüístico-culturales. Este problema se encuentra en los costes adicionales en los que han incurrido los grupos minoritarios, concretamente los inmigrantes de última hora, si desean ser reconocidos como parte genuina del «Nosotros» antes que ser relegados al grupo de «Ellos» en las sociedades en las que el nacionalismo o el separatismo funcionan como instrumentos de promoción para los intereses culturales particulares de la mayoría. Estos costes pueden retrasar notablemente, o incluso entorpecer, la adhesión de dichos grupos a la narrativa nacionalista/secesionista. Si miramos a la situación de Quebec, la misma exigencia de adoptar una lengua minoritaria en el contexto más amplio de Canadá, por muy legítima y aceptable que sea, constituye en y por si misma un coste añadido que otras comunidades sub-estatales, tales como Escocia, no tienen que imponer a sus recién llegados, ya que el idioma común público es el mismo que el de la comunidad global,

70 G. LAFOrest (with J.-O-ROY), Un Québec exilé dans la fédération. Essai d'bistoire intellectuelle et de pensé politique (Montréal: Québec-Amérique, 2014).

71 Sobre el nacionalismo mayoritario, véase: A.-G. GAGnON, A. LeCours \& G. Nootens (eds.), Les nationalismes majoritaires contemporains: identité, mémoire, pouvoir (Montréal: Québec-Amérique, 2007).

UNED. Teoría y Realidad Constitucional, núm. 37, 2016, pp. 135-162 
acentos regionales aparte. La lengua significa en cierto modo un coste de entrada adicional, pero el renacimiento del etno-nacionalismo podría decirse supone una capa más. Por ejemplo, en Quebec, una cosa es pedir a los grupos minoritarios que aprendan y usen el francés en la denominada «esfera pública», y otra muy distinta pedirles que se identifiquen con una narrativa que pone el énfasis en el maltrato de la mayoría franco-canadiense entre la conquista británica de Nueva Francia en 1759 y hoy, especialmente si la concepción del laicismo que se fomenta consagra prejuicios hacia cierto tipos de comportamiento religioso. Pedir que los grupos minoritarios o inmigrantes se adhieran a esta identidad espesa incrementa drásticamente los «costes transaccionales» en los que incurren si quieren ser materialmente considerados, y así comprendidos, como quebequeses genuinos. Esta clase de movimiento es inevitablemente susceptible de disuadirles de hacer suyas, y de internalizar, las narrativas nacionalistas o secesionistas y, más concretamente, convierte a cualquier proyecto secesionista en dudoso. En un contexto en el que, como en Quebec, el mayor crecimiento de la población viene de la inmigración, los acontecimientos políticos recientes en esa provincia ensombrecen la viabilidad a largo plazo del proyecto secesionista. Si hubo un tiempo en que la canción secesionista tenía un ritmo alegre, se ha transformado ahora en una triste melodía.

TITLE: Some Legal and Political Challenges Facing the Quebec Independence Movement

ABSTRACT: Quebec's secessionist movement is one of the oldest of the sort in any democratic country. This paper seeks to provide an overview of some of the main political and legal hurdles currently faced by the Quebec independence movement. First it revisits the domestic legal framework applicable to a provincial secession attempt since the seminal 1998 opinion of the Supreme Court of Canada in Reference re Secession of Quebec, which was a major game changer in the debate over Quebec's potential secession. Then it examines the potential impact of recent political events, as the Scotland's recent referendum process, on the strategy of the Quebec secessionist movement. And last it looks at an alleged new legal foundation for secession, i.e. a so-called "right to decide" distinct from the right to external self-determination.

Resumen: El movimiento secesionista de Quebec, uno de los más antiguos de ese tipo en un país democrático, continúa suscitando interés en otras partes del mundo. Pero este movimiento actualmente se enfrenta importantes desafíos. El objetivo principal de este artículo es de proporcionar a sus lectores una visión general de algunos de los principales obstáculos políticos y legales que afronta en la actualidad el movimiento independentista de Quebec. El primero obstáculo se debe poner en relación con el marco legal aplicable al intento de secesión provincial desde la decisión de 1998, del Tribunal Supremo de Canadá en la Reference re Secession of Quebec. El segundo se encuentra en el impacto potencial del proceso del reciente referéndum en Escocia sobre la estrategia del movimiento secesionista de Quebec. El tercero se creó como consecuencia de la división interna de este movimiento. Por último, se estudia una nueva pretendida base legal para reivindicar la secesión, es decir, el denominado «derecho a decidir», en tanto distinto del derecho a la auto-determinación externa.

KEY WORDS: Independence. Quebec.

Palabras Clave: Independencia. Quebec.

FeCHA DE RECEPCión: 04.09.2015 FeCHA DE ACEPTACión: 15.01.2016 